\title{
Inhibitory effects of bee venom on mast cell-mediated allergic inflammatory responses
}

\author{
YUN-MI KANG ${ }^{1}$, KYUNG-SOOK CHUNG ${ }^{2}$, IN-HOON KOOK ${ }^{1}$, YOON-BUM KOOK ${ }^{3}$, \\ HYUNSU BAE ${ }^{4}$, MINHO LEE ${ }^{2}$ and HYO-JIN AN ${ }^{1}$ \\ ${ }^{1}$ Department of Pharmacology, College of Korean Medicine, Sangji University, Wonju, Gangwon-do 26339; \\ ${ }^{2}$ Catholic Precision Medicine Research Center, College of Medicine, The Catholic University of Korea, Seoul 06591; \\ ${ }^{3}$ Department of Prescription, College of Korean Medicine, Sangji University, Wonju, Gangwon-do 26339; \\ ${ }^{4}$ Department of Physiology, College of Korean Medicine, Kyung Hee University, \\ Dongdaemoon-Gu, Seoul 02447, Republic of Korea
}

Received October 1, 2017; Accepted February 28, 2018

DOI: $10.3892 / \mathrm{ijmm} .2018 .3558$

\begin{abstract}
Although bee venom (BV) is a toxin that causes bee stings to be painful, it has been widely used clinically for the treatment of certain immune-associated diseases. BV has been used traditionally for the treatment of chronic inflammatory diseases. In this regard, the present study analyzed the effect of BV on the regulation of inflammatory mediator production by mast cells and their allergic inflammatory responses in an animal model. HMC-1 cells were treated with BV prior to stimulation with phorbol-12-myristate 13-acetate plus calcium ionophore A23187 (PMACI). The production of allergy-associated pro-inflammatory mediators was examined, and the underlying mechanisms were investigated. Furthermore, to investigate whether BV exhibits anti-inflammatory effects associated with anti-allergic effects in vivo, a compound 48/80-induced anaphylaxis model was used. BV inhibited histamine release, mRNA expression and production of cytokines in the PMACI-stimulated HMC-1 cells. Furthermore, the inhibitory effects of BV on
\end{abstract}

Correspondence to: Professor Hyo-Jin An, Department of Pharmacology, College of Korean Medicine, Sangji University, 83 Sangjidae-gil, Wonju-si, Gangwon-do 26339, Republic of Korea E-mail: hjan@sj.ac.kr

Professor Minho Lee, Catholic Precision Medicine Research Center, College of Medicine, The Catholic University of Korea, 222 Banpo-daero, Seocho-gu, Seoul 06591, Republic of Korea

E-mail: minholee@catholic.ac.kr

Abbreviations: HMC-1, human mast cell; BV, bee venom; PMACI, phorbol-12-myristate 13-acetate plus calcium ionophore A23187; MAPK, mitogen-activated protein kinase; MKK, MAPK kinase; STAT3, signal transducer and activator of transcription 3

Key words: bee venom, mast cell, allergic inflammation, mitogen-activated protein kinase, signal transducer and activator of transcription 3 mitogen-activated protein kinase (MAPK), MAPK kinase, signal transducer and activator of transcription 3 (STAT3) and Akt were demonstrated. The present study also investigated the ability of BV to inhibit compound 48/80-induced systemic anaphylaxis in vivo. BV protected the mice against compound 48/80-induced anaphylactic-associated mortality. Furthermore, BV suppressed the mRNA expression levels of pro-inflammatory cytokines, and suppressed the activation of MAPK and STAT3 in this model. These results provide novel insights into the possible role of $\mathrm{BV}$ as a modulator for mast cell-mediated allergic inflammatory disorders.

\section{Introduction}

Allergic inflammation is characterized by pathophysiological or medical disabilities, including allergic asthma, atopic dermatitis, eczema, allergic rhinitis and anaphylaxis, following exposure to allergens or harmful stimuli, including pathogens, damaged cells and irritants (1). An allergic reaction is the result of an inappropriate immune response, for example, hypersensitivity-triggered inflammation. This inflammation is associated with pro-inflammatory mediators, including histamine, cytokines and chemokines, secreted from mast cells (2). Mast cells are traditionally viewed as effector cells of immediate hypersensitivity reactions. Mast cells are important in specific immunity through the interaction of multivalent antigens with $\operatorname{IgE}$ bound to the high-affinity $\operatorname{IgE}$ receptor (FceRI) on these cells. Upon allergen provocation, mast cells release inflammatory mediators, which trigger the process of degranulation in activated mast cells $(3,4)$.

The mitogen-activated protein kinase (MAPK) signaling cascade controls important cellular processes, including gene expression, cell proliferation, cell survival and death, and cell mobility (5). The activation of MAPKs is associated with allergic inflammatory responses via the translocation of nuclear factor- $\kappa \mathrm{B}(\mathrm{NF}-\kappa \mathrm{B})$, which causes the production of pro-inflammatory cytokines and chemokines (6). In mammalian systems, there are three well-characterized subfamilies of MAPKs. These include the extracellular signal-regulated kinases 
(ERKs), the p38 MAPKs and the c-Jun N-terminal kinases (JNKs) (7). These pathways are linear kinase cascades in which MAPK kinase (MKK) kinase phosphorylates and activates MKK, which in turn phosphorylates and activates MAPK. The MKK family members are unique in that they are dual-specificity kinases, phosphorylating MAPKs on threonine and tyrosine residues (8). MKKs are essential components of the evolutionarily conserved MAPK signaling cascade, which regulates a variety of cellular activities and innate immune responses. Numerous studies have been performed to investigate the role of MKKs in the innate immune system (9).

As several cytokines promote allergic inflammation through cytokine receptors, the signal transducer and activator of transcription (STAT) family of proteins have obligate roles in pro-allergic cytokine-induced gene regulation in multiple cell types (10). STATs have been implicated as the key transcription factors in immunity and inflammatory pathways (11). However, the role of the STAT pathway in mast cells remains to be fully elucidated. STAT3, a key cytoplasmic transcription factor involved in inflammation, becomes activated in response to various cytokines, chemokines and growth factors. The activation of STAT3 requires the phosphorylation of tyrosine residue 705 (Tyr705), leading to protein dimerization and translocation from the cytoplasm to the nucleus (12). Activated STATs dimerize and translocate to the nucleus, where they bind to specific promoter sequences and induce the transcription of several target genes.

Bee venom (BV), which is extracted from honey bees, is a bitter and colorless liquid, and its active portion contains a mixture of proteins that cause local inflammation and act as an anticoagulant (13). It has been reported that the majority of cases of humans succumbing to mortality as a result of one or multiple bee stings are due to allergic reactions, heart failure, or suffocation from swelling around the neck or the mouth. Compared with other diseases, accidents and other unusual cases, bee sting-associated mortality is rare, indicating that $\mathrm{BV}$ is safe for treating human diseases (14). BV therapy is a form of medicine, which originated from ancient Greece and China (15). Due to its anti-inflammatory (16), antibacterial (17), antinociceptive (18), hepatocyte-protective (19) and anticancer characteristics (20), it has a long history of use in folk medicine to treat various diseases. In Korea, BV has long been used to relieve pain and to treat several diseases, including arthritis (21), rheumatism (22), rhinitis (23), cancer (24), asthma (25) and skin diseases (26). The collected $\mathrm{BV}$ is purified in aseptic conditions and lyophilized for clinical use at a concentration suitable for the patient's symptoms and conditions.

BV contains a variety of different peptides, including melittin, apamin, adolapin and mast cell degranulating (MCD) peptide. The two main components of $\mathrm{BV}$, melittin and adolapin, have anti-inflammatory effects, which involve the inhibited expression of cyclooxygenase- 2 and phospholipase A2, and decreased levels of tumor necrosis factor- $\alpha$ (TNF- $\alpha$ ), interleukin(IL)-1, IL-6 and nitric oxide (23). These components are known to exert their pharmacological effects individually or interactively depending on their concentration or dose. Although several studies have demonstrated the anti-allergic inflammatory effects of BV and its components in a number of cell types, the exact molecular mechanism underlying the effect of BV in mast cells has not been investigated. In the present study, the inhibitory effects of BV on the mRNA expression and production of pro-inflammatory cytokines and the associated molecular signaling pathways were investigated in phorbol-12-myristate 13-acetate plus calcium ionophore A23187 (PMACI)-stimulated HMC-1 cells and in a compound 48/80-induced anaphylaxis animal model.

\section{Materials and methods}

Chemicals and reagents. For the present study, BV (from Apis mellifera), phorbol 12-myristate 13-acetate (PMA), calcium ionophore A23187 (Calcimycin; $\mathrm{C}_{29} \mathrm{H}_{37} \mathrm{~N}_{3} \mathrm{O}_{6}$ ) and all other chemicals were purchased from Sigma; EMD Millipore (Billerica, MA, USA). 3-(4,5-dimethylthiazol-2-yl)-5-(3-carb oxymethoxyphenyl)-2-(4-sulfophenyl)-2H-tetrazolium (MTS) was purchased from Promega Corporation (Madison, WI, USA). Iscove's modified Dulbecco's medium (IMDM), fetal bovine serum (FBS), penicillin and streptomycin were obtained from Thermo Fisher Scientific, Inc. (Waltham, MA, USA). Primary antibodies against ERK (cat. no. 9102), phosphorylated (p-)JNK (cat. no. 9251), JNK (cat. no. 9252), p-p38 (cat. no. 9215), p38 (cat. no. 9212), p-Akt (cat. no. 9271), p-MKK3/6 (cat. no. 12280), p-MKK4 (cat. no. 9156), MKK4 (cat. no. 9152), p-STAT3 (Tyr705; cat. no. 9145) and p-STAT3 (Ser727; cat. no. 9134) were obtained from Cell Signaling Technology, Inc. (Danvers, MA, USA). Primary antibodies for p-ERK (cat. no. sc-7383), p-MAPK kinase 1/2 (MEK1/2; cat. no. sc-81503), MEK1/2 (cat. no. sc-81504), MKK3/6 (cat. no. sc-13069), Akt (cat. no. sc-8312) and STAT3 (cat. no. sc-8019), $\beta$-actin (cat. no. sc-81178) were purchased from Santa Cruz Biotechnology, Inc. (Santa Cruz, CA, USA). Horseradish peroxidase-conjugated secondary antibodies were purchased from Jackson ImmunoResearch Laboratories, Inc. (West Grove, PA, USA). The histamine enzyme-linked immunosorbent assay (ELISA) kit was obtained from Enzo life Sciences, Inc. (Farmingdale, NY, USA). The ELISA kits for TNF- $\alpha$, IL- 6 , and IL- $1 \beta$ were obtained from R\&D Systems, Inc. (Minneapolis, MN, USA). SYBR Premix Ex Taq was purchased from Takara Bio, Inc. (Shiga, Japan). TNF- $\alpha$, IL-6, IL-1 $\beta$, and GAPDH oligonucleotide primers were purchased from Bioneer Corporation (Daejeon, Korea).

Cell culture and sample treatment. HMC-1 cells were provided by Professor Jae-Young Um (Kyung Hee University, Republic of Korea), and were grown at $37^{\circ} \mathrm{C}$ in IMDM supplemented with $10 \%$ FBS, penicillin $(100 \mathrm{U} / \mathrm{ml})$ and streptomycin $(100 \mu \mathrm{g} / \mathrm{ml})$ in a humidified atmosphere of $5 \% \mathrm{CO}_{2}$. The $\mathrm{BV}$ was dissolved in distilled water and filtered using Acrodisc ${ }^{\circledR}$ Syringe Filters 0.2- $\mu \mathrm{m}$ Supor ${ }^{\circledR}$ Membrane (Pall Life Sciences, Port Washington, NY, USA). HMC-1 cells were seeded at a density of $1 \times 10^{6}$ cell per well, and then treated with BV at concentrations of 5 and $10 \mu \mathrm{g} / \mathrm{ml}$ for $30 \mathrm{~min}$ at $37^{\circ} \mathrm{C}$ in humidified air with $5 \% \mathrm{CO}_{2}$, and then stimulated with $40 \mathrm{nM}$ of PMA and $1 \mu \mathrm{M}$ of $\mathrm{A} 23187$ (PMACI) at $37^{\circ} \mathrm{C}$ for $5-30 \mathrm{~min}, 6$ and $12-24 \mathrm{~h}$ for the western blot analysis, reverse transcription-quantitative polymerase chain reaction (RT-qPCR) and ELISA, respectively. The various concentrations of test compounds dissolved in distilled water were added together with PMACI. The cells were either treated with media or vehicle control. 
Histamine assay. The HMC-1 cells were pre-treated with BV for $30 \mathrm{~min}$ and then stimulated with $40 \mathrm{nM}$ of PMA and $1 \mu \mathrm{M}$ of $\mathrm{A} 23187$ (PMACI) for $12 \mathrm{~h}$. The conditioned medium was collected and used as a sample. The release of histamine was measured using an ELISA kit in accordance with the manufacturer's protocol.

Cytokine assays. Culture media were collected at 12, 18, and $24 \mathrm{~h}$ post-treatment with $\mathrm{BV}$ and stored at $-70^{\circ} \mathrm{C}$. The levels of TNF- $\alpha$, IL- 6 and IL- $1 \beta$ were measured using ELISA kits according to the manufacturer's protocol.

Western blot analysis. Segments of cells or liver tissue were suspended in PRO-PREPTM protein extraction solution (Intron Biotechnology, Inc., Seoul, Korea) and incubated for $20 \mathrm{~min}$ at $4^{\circ} \mathrm{C}$. Cell debris was removed via micro-centrifugation $11,000 \mathrm{x}$ g for $30 \mathrm{~min}$ at $4^{\circ} \mathrm{C}$, followed by rapid freezing of the supernatant. The protein concentration was determined using Bio-Rad protein assay reagent (Bio-Rad Laboratories, Inc., Hercules, CA, USA) according to the manufacturer's protocol. Cellular proteins from the treated and untreated cell extracts (10-30 $\mu \mathrm{l})$ were electroblotted onto a polyvinylidene fluoride membrane following separation via 10-12\% SDS-PAGE. The membrane was incubated for $1 \mathrm{~h}$ with blocking solution (5\% skim milk) at room temperature, followed by overnight incubation with the primary antibodies $(1: 1,000)$ at $4^{\circ} \mathrm{C}$. The blots were washed three times with Tween 20/Tris-buffered saline (T/TBS) and incubated with horseradish peroxidase-conjugated secondary antibody $(1: 2,000)$ for $2 \mathrm{~h}$ at room temperature. The blots were washed three times with T/TBS, and then developed via enhanced chemiluminescence (GE Healthcare Life Sciences, Chalfont, UK). Densitometric analysis was performed using Bio-Rad Quantity One software version 4.3.0 (Bio-Rad Laboratories, Inc.).

RT-qPCR analysis. Total RNA was isolated from the cells or liver tissues using an Easy Blue kit (Intron Biotechnology, Inc.) according to the manufacturer's protocol. Total RNA was quantified using an Epoch micro-volume spectrophotometer system (BioTek Instruments, Inc., Winooski, VT, USA). cDNA was obtained using isolated total RNA $(2 \mu \mathrm{g}), \mathrm{d}(\mathrm{T}) 16$ primer, and Avian Myeloblastosis Virus reverse transcriptase with genomic DNA remover. The relative gene expression was quantified using RT-qPCR analysis (Real Time PCR System 7500; Applied Biosystems; Thermo Fisher Scientific, Inc.) with SYBR Premix Ex Taq. Each reaction tube contained $0.4 \mu 1$ forward primer, $0.4 \mu 1$ reverse primer, $7.2 \mu 1$ diethyl pyrocarbonate water, $10 \mu \mathrm{l} \mathrm{SYBR}$ and $2 \mu \mathrm{l}$ cDNA template (10 ng/ $\mu \mathrm{l})$. The PCR cycling conditions were as follows: $10 \mathrm{~min}$ at $95^{\circ} \mathrm{C} ; 40$ cycles of $5 \mathrm{sec}$ at $95^{\circ} \mathrm{C}$ and $45 \mathrm{sec}$ at $60^{\circ} \mathrm{C}$; and a final melting curve of $15 \mathrm{sec}$ at $95^{\circ} \mathrm{C}, 1 \mathrm{~min}$ at $60^{\circ} \mathrm{C}$, and $15 \mathrm{sec}$ at $95^{\circ} \mathrm{C}$. The oligonucleotide primers were as follows: Human TNF- $\alpha$, forward 5'-GCTGGAGAAGGGTGACCGAC-3' and reverse 5'-GTTCGTCCTCCTCACAGGGC-3'; mouse TNF- $\alpha$, forward 5'-ATGAGCACAGAAAGCATGAT-3' and reverse 5'-TACAGGCTTGTCACTCGAAT-3'; human IL-6, forward 5'-ATTCCGGGAACGAAAGAGAA-3' and reverse 5'-TCTTCTCCTGGGGGTACTGG-3'; mouse IL-6, forward 5'-TTCCATCCAGTTGCCTTCTTG-3' and reverse 5'-GGG AGTGGTATCCTCTGTGAAGTC-3'; human IL-1 $\beta$, forward
5'-TGGACCTCTGCCCTCTGGAT-3' and reverse 5'-GGC AGGGAACCAGCATCTTC-3'; for mouse IL-1 $\beta$, forward 5'-GATCCACACTCTCCAGCTGCA-3' and reverse 5'-CAA CCAACA AGTGATATTCTCCATG-3'; human GAPDH, forward 5'-CTCCTCCACCTTTGACGCTG-3' and reverse 5'-CTCTTGTGCTCTTGCTGGGG-3'; mouse GAPDH, forward 5'-GACGGCCGCATCTTCTTGT-3' and reverse 5'-CACACCGACCTTCACCATTTT-3'. The size of the synthesized cDNAs was 100-150 bp. Fold changes of gene expression were calculated using the comparative quantification cycle $(\mathrm{Cq})$ method (Applied Biosystems; Thermo Fisher Scientific, Inc.) (27). The Cq values of target genes TNF- $\alpha$, IL- 6 and IL-1 $\beta$ were normalized to that of GAPDH using the ABI gene express 2.0 program (Applied Biosystems; Thermo Fisher Scientific, Inc.).

Compound 48/80-induced anaphylactic shock model. A total of 24 ICR male mice (6 weeks old; 20-25 g body weight) were obtained from Raon Bio (Yongin, Korea) and maintained under constant conditions at a temperature of $20-25^{\circ} \mathrm{C}$, humidity of $40-60 \%$ and a 12 -h light/dark cycle. The mice were randomly assigned to one of four groups $(n=6$ per group). The ICR mice were injected intraperitoneally (i.p.) with phosphate-buffered saline (PBS) or compound 48/80 (8 $\mathrm{mg} / \mathrm{kg}$ dissolved in PBS) as described previously $(28,29)$. BV or disodium cromoglycate (DSCG; Sigma-Aldrich; EMD Millipore) or PBS were dissolved in saline and injected i.p. at doses of $25 \mathrm{mg} / \mathrm{kg}$ DSCG and $20 \mathrm{mg} / \mathrm{kg} \mathrm{BV}$ for $1 \mathrm{~h}$ prior to the compound $48 / 80$ injection. Survival was monitored for $1 \mathrm{~h}$ following the induction of anaphylactic shock. Survival data were analyzed using the Kaplan-Meier method and logrank test. Following the assessment of animal survival, blood was collected from the heart of each mouse to measure serum cytokine production. The blood was allowed to clot for $1 \mathrm{~h}$ at room temperature and then centrifuged for $20 \mathrm{~min}$ at $3,000 \mathrm{x} \mathrm{g}$ at $4^{\circ} \mathrm{C}$ to obtain serum. Following collection of blood samples from the mice, the mice were sacrificed by cervical dislocation. All procedures were performed in accordance with university guidelines and approved by the Ethical Committee for Animal Care and the Use of Laboratory Animals, Korean Medicine, Sangji University (Wonju, Korea; approval no. 2015-11).

Statistical analysis. The data are expressed as the mean \pm standard deviation of triplicate experiments. Statistically significant differences were compared using one-way analysis of variance and Dunnett's post hoc test. $\mathrm{P}<0.05$ was considered to indicate a statistically significant difference. Statistical analysis was performed using SPSS statistical analysis software (version 19.0; IBM SPSS, Armonk, NY, USA).

\section{Results}

$B V$ suppresses PMACI-induced histamine release, and production and $m R N A$ expression of pro-inflammatory cytokines in HMC-1 cells. The present study evaluated the cytotoxic effect of various concentrations of $\mathrm{BV}$ $(0.625,1.25,2.5,5,10$ and $20 \mu \mathrm{g} / \mathrm{ml})$ on HMC- 1 cells. After $4 \mathrm{~h}$, the cells were treated with BV and incubated for an additional $24 \mathrm{~h}$. Cytotoxicity in the HMC-1 cell line was determined using 

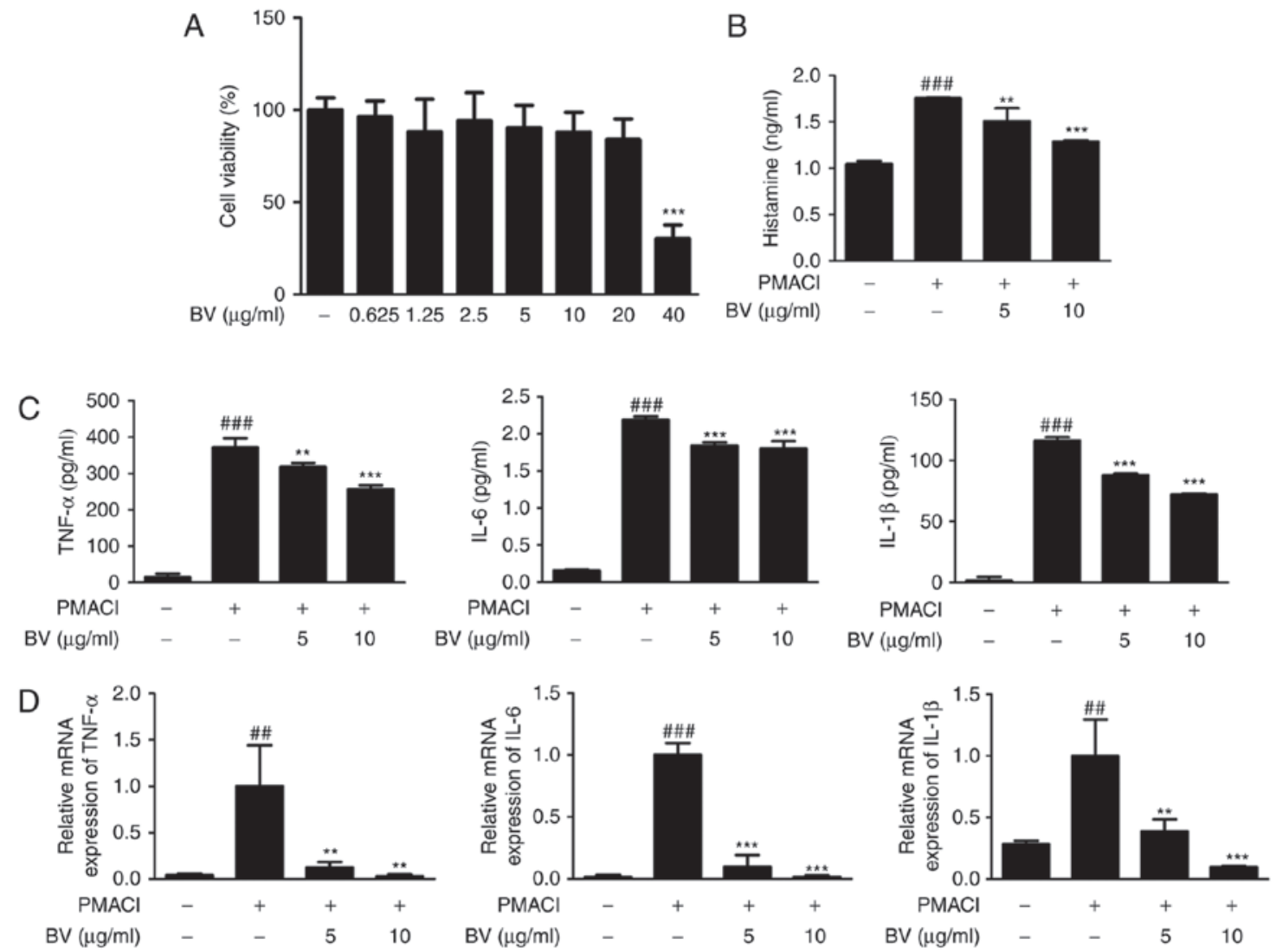

Figure 1. Effect of BV on histamine release and pro-inflammatory cytokines in PMACI-stimulated HMC-1 cells. (A) HMC-1 cells were treated with different concentrations of BV for $24 \mathrm{~h}$, and their viability was determined using a 3-(4,5-dimethylthiazol-2-yl)-5-(3-carboxymethoxyphenyl)-2-(4-sulfophenyl)-2H-tetrazolium assay. (B) Cells were pre-treated with $\mathrm{BV}$ for $30 \mathrm{~min}$ prior to the addition of $40 \mathrm{nM}$ PMA $+1 \mu \mathrm{M}$ PMACI, and the cells were incubated for $12 \mathrm{~h}$. Histamine release in the culture medium was measured using an ELISA kit. (C) HMC-1 cells were treated with 5 and $10 \mu \mathrm{g} / \mathrm{ml}$ of BV for $30 \mathrm{~min}$ prior to the addition of $40 \mathrm{nM}$ PMA $+1 \mu \mathrm{M}$ PMACI and the cells were incubated for 12,18 and $24 \mathrm{~h}$ for the determination of TNF- $\alpha$, IL- 6 and IL- $1 \beta$ production, respectively. Cytokine production was measured using an ELISA kit. (D) Cells were pre-treated with BV for 30 min prior to the addition of $40 \mathrm{nM}$ PMA $+1 \mu \mathrm{M}$ PMACI for $6 \mathrm{~h}$. The mRNA levels of TNF- $\alpha$, IL- 6 and IL- $1 \beta$ were determined using reverse transcription-quantitative polymerase chain reaction analysis. Values are presented as the mean \pm standard deviation of three independent experiments. ${ }^{\# \#} \mathrm{P}<0.01$ and ${ }^{\# \# \#} \mathrm{P}<0.001$, vs. control group; ${ }^{* * *} \mathrm{P}<0.01$ and ${ }^{* * * *} \mathrm{P}<0.001$, vs. PMACI-treated group. BV, bee venom; PMA, phorbol 12-myristate 13-acetate; PMACI, phorbol-12-myristate 13-acetate plus calcium ionophore A23187; ELISA, enzyme-linked immunesorbent assay; TNF- $\alpha$, tumor necrosis factor- $\alpha$; IL, interleukin.

the MTS assay. BV did not cause nonspecific cytotoxicity, as it had no effect on cell viability at concentrations between 0.625 and $20 \mu \mathrm{g} / \mathrm{ml}$ (Fig. 1A).

Among the inflammatory mediators released from mast cells, histamine is known to be the most well-characterized mediator implicated in the acute phase of hypersensitivity, including anaphylactic shock (30). To determine whether BV inhibits histamine release in the culture medium from mast cells, the PMACI-induced histamine release was measured. $\mathrm{BV}$ at a dose of 5 and $10 \mu \mathrm{g} / \mathrm{ml}$ decreased the PMACI-induced histamine levels (Fig. 1B). To determine the inhibitory effect of BV on pro-inflammatory cytokine production, its effect on the PMACI-induced production and mRNA expression of TNF- $\alpha$, IL- 6 and IL- $1 \beta$ and were investigated using ELISA and RT-qPCR analysis, respectively (Fig. 1C and D). Pre-treatment of cells with BV downregulated the PMACI-induced production and mRNA expression of TNF- $\alpha$, IL- 6 and IL- $1 \beta$ in a concentration-dependent manner. These results indicated that $\mathrm{BV}$ exerted potential protection via the inhibition of histamine release during allergic reaction and regulates the PMACI-induced expression of TNF- $\alpha$, IL- 6 and IL- $1 \beta$ through transcriptional inhibition.
$B V$ suppresses the activation of PMACI-induced MAPKs and MKKs in HMC-1 cells. The MAPK cascade is one of the important signaling pathways in immune responses, and is activated in response to diverse extracellular stimuli, leading to the activation of mast cells during allergic inflammation (31). To investigate the effect of BV on MAPK signaling pathways in PMACI-stimulated HMC-1 cells, the phosphorylation of the three MAPK signaling molecules, ERK, JNK and p38, were analyzed using western blot analysis. As shown in Fig. 2A, PMACI significantly induced the phosphorylation of ERK, JNK and $\mathrm{p} 38$, whereas BV suppressed the PMACI-induced activation of these MAPKs. BV did not affect the total levels of MAPKs.

The MAPK isoforms are activated by the dual phosphorylation of threonine and tyrosine residues. MKKs phosphorylate and activate MAPKs (32). To investigate the upstream targets of MAPKs, the present study examined whether BV prevents the PMACI-induced phosphorylation of MEK1/2, MKK3/6 and MKK4. It was found that cells pre-treated with BV significantly suppressed the phosphorylation of MEK1/2, MKK3/6 and MKK4, compared with those treated with PMACI alone; however, the total levels of MKKs were not affected (Fig. 2B). 


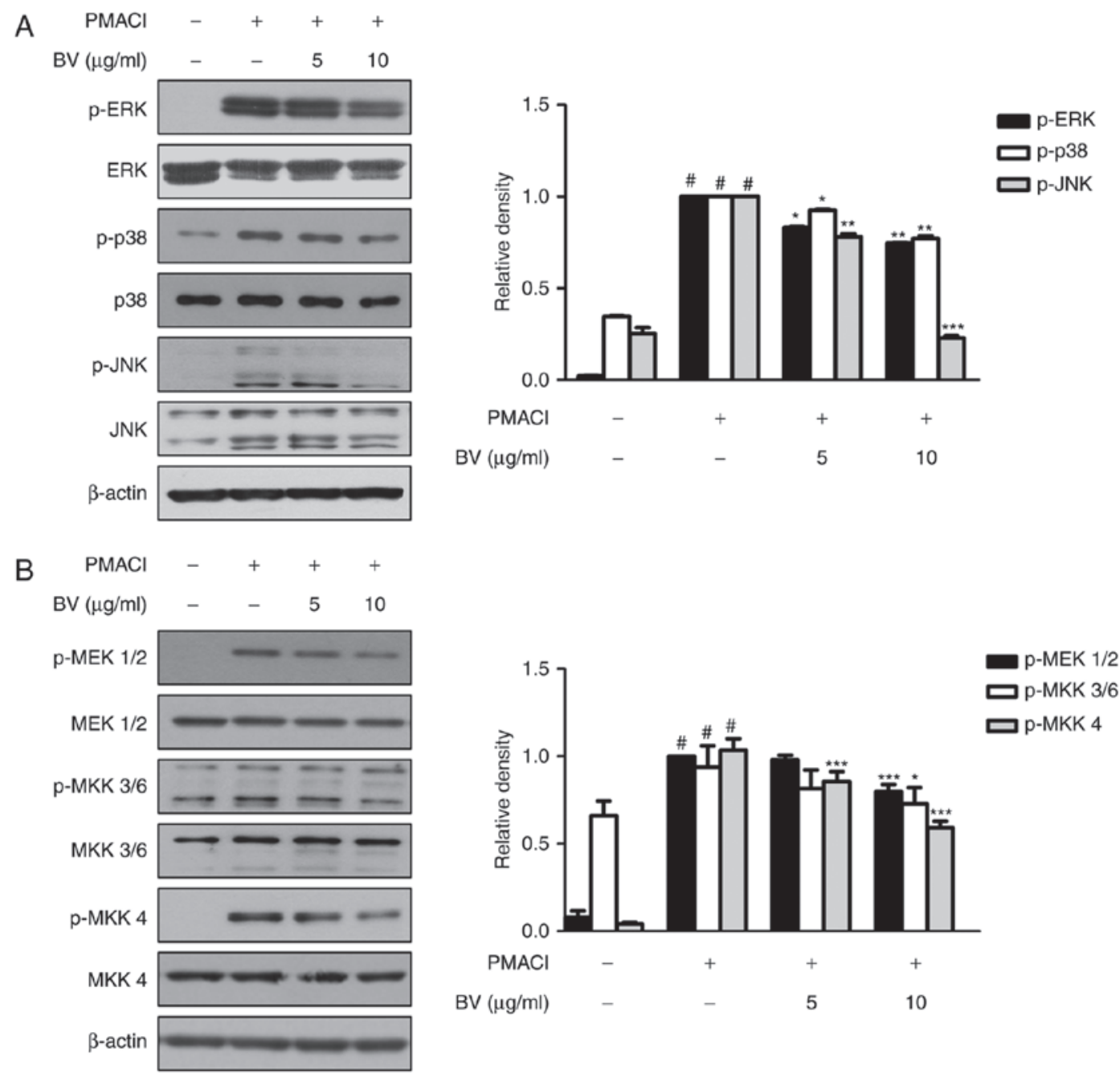

Figure 2. Effect of BV on PMACI-induced activation of mitogen-activated protein kinase and MKKs in HMC-1 cells. (A) HMC-1 cells were pre-treated with 5 and $10 \mu \mathrm{g} / \mathrm{ml}$ of BV for 30 min prior to the addition of $40 \mathrm{nM}$ PMA $+1 \mu \mathrm{M}$ of PMACI for $30 \mathrm{~min}$. (B) HMC- 1 cells were pre-treated with 5 and $10 \mu \mathrm{g} / \mathrm{ml}$ of $\mathrm{BV}$ for $30 \mathrm{~min}$ prior to the addition of $40 \mathrm{nM}$ PMA $+1 \mu \mathrm{M}$ PMACI for $5 \mathrm{~min}$ (p-MEK1/2) or for $10 \mathrm{~min}$ (p-MKK3/6 and p-MKK4). Total proteins were prepared, and western blot analysis was performed using specific antibodies. $\beta$-actin was used as an internal control. Proteins were prepared, and western blot analysis was performed using specific antibodies. ${ }^{*} \mathrm{P}<0.05$, vs. control group; ${ }^{*} \mathrm{P}<0.05,{ }^{* *} \mathrm{P}<0.01$ and ${ }^{* * *} \mathrm{P}<0.001$, vs. PMACI-treated group. BV, bee venom; PMA, phorbol 12-myristate 13-acetate; PMACI, phorbol-12-myristate 13-acetate plus calcium ionophore A23187; MEK1/2, MAPK kinase 1/2; MKK, MAPK kinase; ERK, extracellular signal-regulated kinase; JNK, c-Jun N-terminal kinase; p-, phosphorylated.

BV suppresses the PMACI-induced activation of STAT3 and Akt in HMC-1 cells. STAT3 has been implicated as a key transcription factor in inflammatory pathways (11). In addition, Akt is a multifunctional mediator of the activation of phosphoinositide 3-kinase (PI3K) in various cell types, and STAT3 is interconnected with PI3K $(33,34)$. Therefore, the present study examined the effect of BV on the PMACI-stimulated phosphorylation of STAT3 and Akt. As shown in Fig. 3A, PMACI induced the phosphorylation of STAT3 on Ser727, whereas BV pre-treatment suppressed the PMACI-induced activation of STAT3 on Ser727, but did not affect the phosphorylation of STAT3 on Tyr705. Pre-treatment with BV also significantly suppressed the phosphorylation of Akt, compared with that in cells treated with PMACI alone (Fig. 3B).

$B V$ has anti-allergic inflammatory effects on compound 48/80-induced hypersensitivity in an animal model of anaphylaxis. To assess the anti-allergic inflammatory effect of $\mathrm{BV}$ in vivo, the present study investigated its effect on the survival rate of mice with compound 48/80-induced hypersensitive anaphylaxis. In this experiment, $8 \mathrm{mg} / \mathrm{kg}$ compound $48 / 80$ was used, which was considered a suitable concentration for investigating the anaphylactic response in previous studies $(35,36)$. Following i.p. injection of compound $48 / 80$, all mice were monitored for $1 \mathrm{~h}$ and their survival rates were determined. When the mice were pre-treated with $\mathrm{BV}$ at a dose of $20 \mathrm{mg} / \mathrm{kg}$ for $1 \mathrm{~h}$ prior to the administration of compound 40/80, their mortality rates were reduced (Fig. 4A).

To evaluate cytokine levels in response to the allergic reaction, the mRNA levels of cytokines in the liver of anaphylactic mice were examined. As shown in Fig. 4B, compound 48/80 administration markedly increased the mRNA levels of TNF- $\alpha$, IL-6 and IL-1 $\beta$, whereas pre-treatment with BV $(20 \mathrm{mg} / \mathrm{kg}$, i.p.) for $1 \mathrm{~h}$ prior to compound $48 / 80$ administration significantly decreased the expression levels of these pro-inflammatory cytokines. These results indicated that BV provides protection via the inhibition of cytokine release during a systemic anaphylactic reaction. 

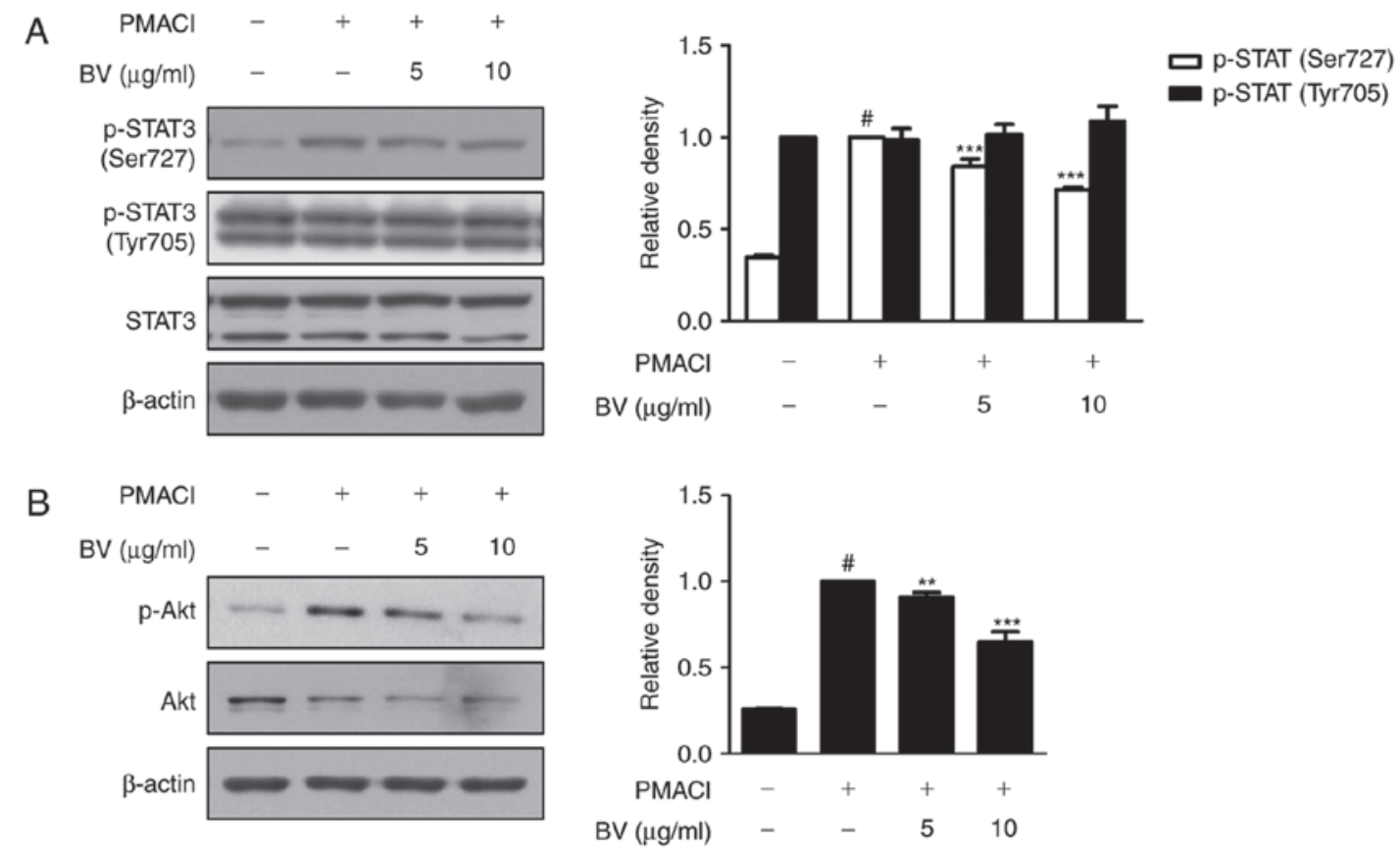

Figure 3. Effect of BV on PMACI-induced activation of STAT3 and Akt in HMC-1 cells. (A) HMC-1 cells were pre-treated with $5 \mathrm{and} 10 \mu \mathrm{g} / \mathrm{ml}$ of BV for $30 \mathrm{~min}$ prior to the addition of $40 \mathrm{nM}$ PMA $+1 \mu \mathrm{M}$ PMACI $30 \mathrm{~min}$ (p-STAT3 Ser727) or for $10 \mathrm{~min}$ (p-STAT3 Tyr705). Total proteins were prepared, and western blot analysis was performed using specific antibodies. (B) HMC-1 cells were pre-treated with $5 \mathrm{and} 10 \mu \mathrm{g} / \mathrm{ml}$ of BV for 30 min prior to the addition of $40 \mathrm{nM}$ PMA $+1 \mu \mathrm{M}$ PMACI for $5 \mathrm{~min}$. $\beta$-actin was used as an internal control. Proteins were prepared, and western blot analysis was performed using specific antibodies. ${ }^{~ P}<0.05$, vs. control group; ${ }^{* *} \mathrm{P}<0.01$ and ${ }^{* * * *} \mathrm{P}<0.001$, vs. PMACI-treated group. BV, bee venom; PMA, phorbol 12-myristate 13-acetate; PMACI, phorbol-12-myristate 13-acetate plus calcium ionophore A23187; STAT3, signal transducer and activator of transcription 3; p-, phosphorylated.

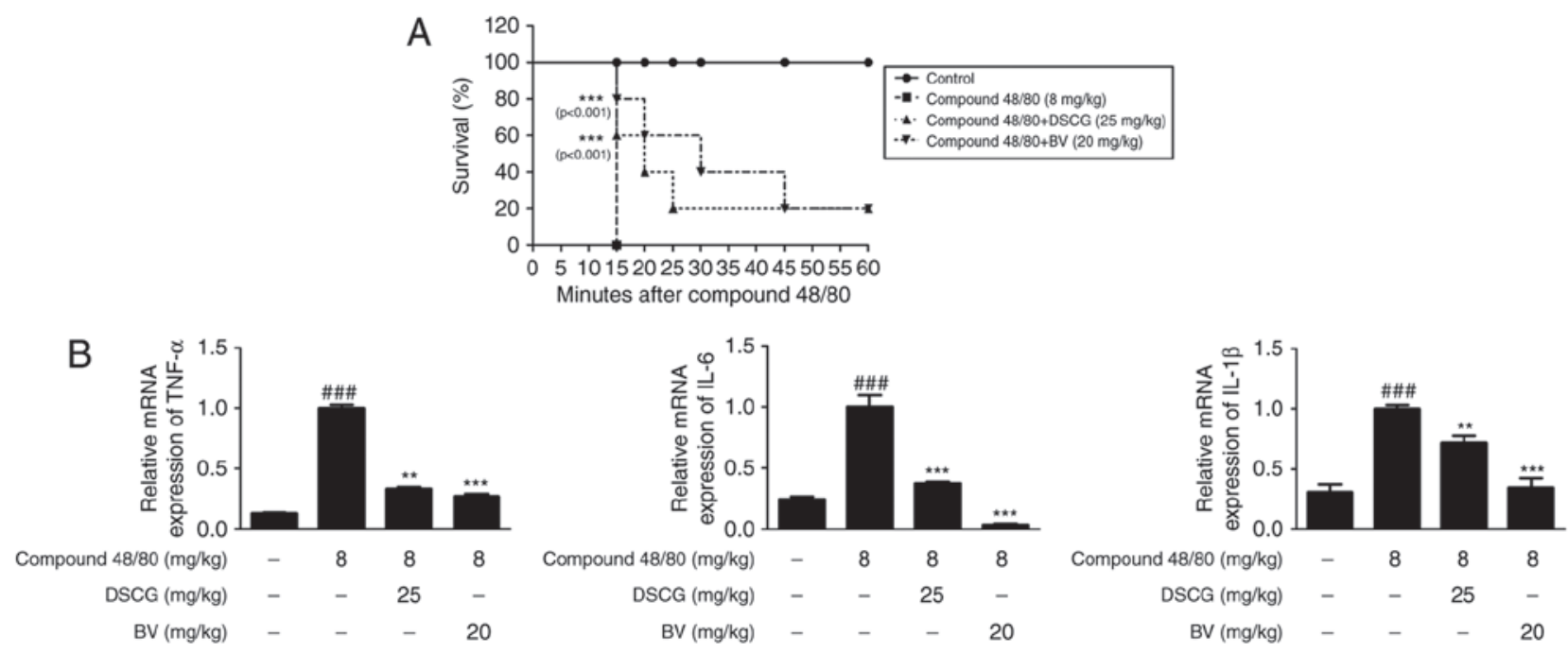

Figure 4. Effects of BV on compound 48/80-induced mortality and inflammatory cytokines in an anaphylactic shock animal model. Mice were injected with BV, DSCG and PBS as a vehicle ( $\mathrm{n}=6$ per group or total) for $1 \mathrm{~h}$ prior to compound $48 / 80$ injection $(8 \mathrm{mg} / \mathrm{kg}$ i.p.). (A) Survival rates of the mice were monitored for $1 \mathrm{~h}$. (B) Total RNA was prepared from the liver tissue, and the levels of TNF- $\alpha$, IL- 6 and IL-1 $\beta$ were determined using reverse transcription-quantitative polymerase chain reaction analysis. Densitometric analysis was performed using Bio-Rad Quantity One ${ }^{\circledR}$ software. The data shown are presented as the mean \pm standard deviation of three independent experiments. ${ }^{\# \# "} \mathrm{P}<0.001$, vs. control group; ${ }^{* *} \mathrm{P}<0.01$ and ${ }^{* * * *} \mathrm{P}<0.001$, vs. compound $48 / 80$-treated group. BV, bee venom; DSCG, disodium cromoglycate; PBS, phosphate-buffered saline; TNF- $\alpha$, tumor necrosis factor- $\alpha$; IL, interleukin.

$B V$ suppresses the compound 48/80-induced activation of MAPKs and STAT3 in an animal model of anaphylaxis. To investigate the role of BV in the activation of MAPK and STAT3 in animal model of anaphylaxis, the present study determined the protein levels of MAPKs and STAT3 using western blot analysis. As shown in Fig. 5A and B, the administration of BV inhibited the compound 48/80-induced phosphorylation of MAPKs. BV inhibited the compound 48/80-induced phosphorylation of STAT3 on Tyr705, but did not affect the phosphorylation of STAT3 on Ser727. These results demonstrated that BV exerted suppressive effects on allergic inflammation via the regulation of MAPK and STAT3 activation in this model of anaphylactic shock. 


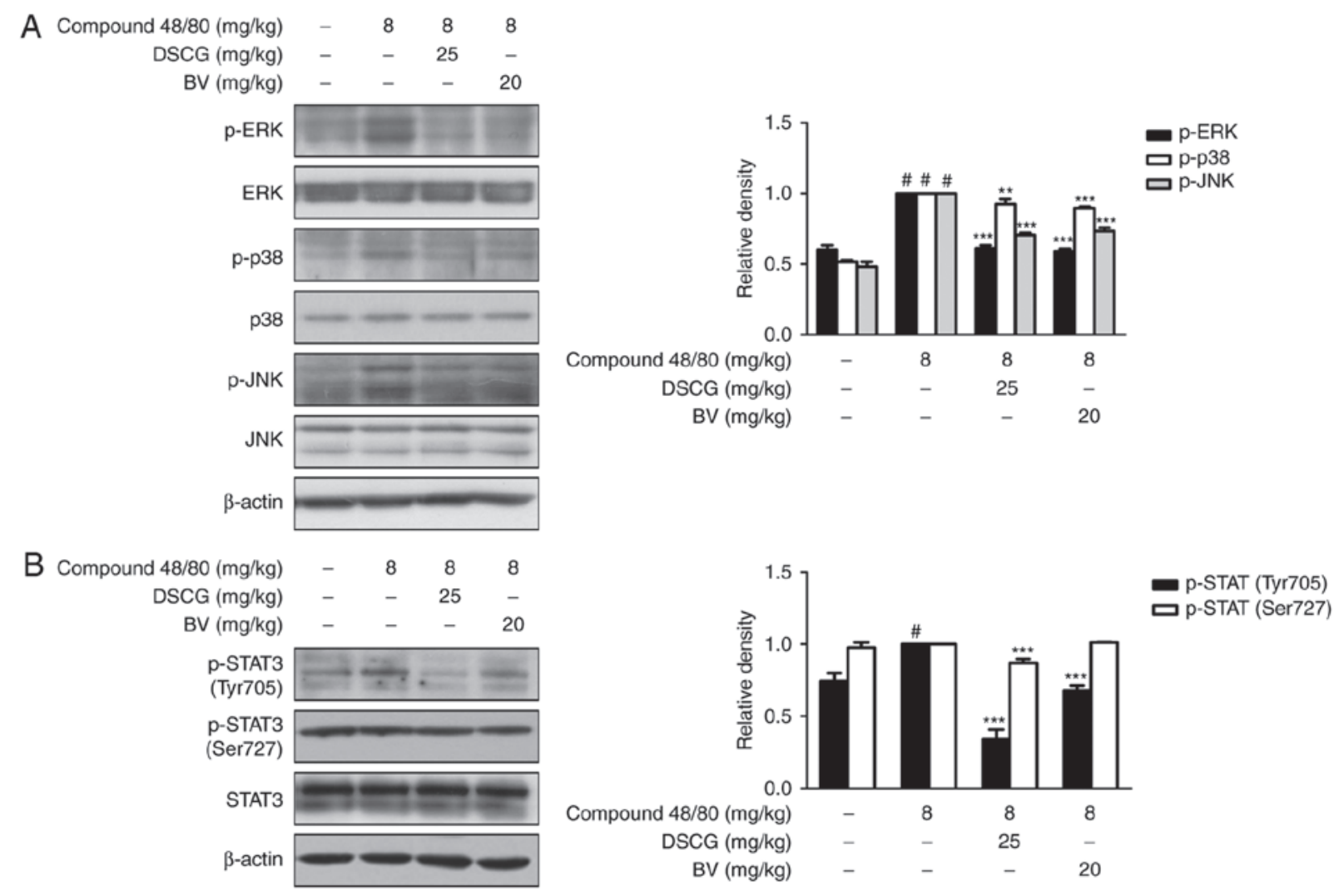

Figure 5. Effects of BV on compound 48/80-induced activation of MAPKs and STAT3 in an anaphylactic shock animal model. Mice were injected with BV, DSCG and PBS as a vehicle ( $\mathrm{n}=6$ per group or total) for $1 \mathrm{~h}$ prior to compound $48 / 80$ injection $(8 \mathrm{mg} / \mathrm{kg}$ i.p.). Expression levels of (A) MAPKs and (B) STAT3 were determined by western blot analysis using specific antibodies. Densitometric analysis was performed using Bio-Rad Quantity One ${ }^{\circledR}$ software. The data shown are presented as the mean \pm standard deviation of three independent experiments. ${ }^{*} \mathrm{P}<0.05$, vs. control group; ${ }^{* *} \mathrm{P}<0.01$ and ${ }^{* * *} \mathrm{P}<0.001$, vs. compound 48/80-treated group. BV, bee venom; PBS, phosphate-buffered saline; DSCG, disodium cromoglycate; MAPK, mitogen-activated protein kinase; ERK, extracellular signal-regulated kinase; JNK, c-Jun N-terminal kinase; STAT3, signal transducer and activator of transcription 3; p-, phosphorylated.

\section{Discussion}

Allergic inflammation is classified into two phases, early-phase (or type immediate hypersensitivity) and late-phase reactions, which result in subsequent chronic allergic inflammation (1). Early-phase immediate hypersensitivity occurs within minutes of allergen exposure and is induced by the release of preformed mediators, including histamine and tryptases, chemotactic factors from activated mast cells (37). In particular, histamine is chemically classified as an amine, and is the most potent mediator with various biological roles, including in anaphylactic shock, inflammation and neurotransmission (38). By contrast, late-phase reactions are the result of pro-inflammatory cytokine production and the recruitment of immune cells, including neutrophils, basophils, eosinophils, macrophages and mast cells, to sites of inflammation. In accordance with these reports, the mast cell number increases in atopic dermatitis, allergic rhinitis and asthma, and the pro-inflammatory cytokines, TNF- $\alpha$, IL-6, IL-8 and IL-1 $\beta$, released by mast cells enhance the inflammatory process (39). These cytokines are associated with biological functions, including regulation of cell proliferation, differentiation and immunity, with recruitment of additional immune cells to inflammatory sites being the main function $(40,41)$.

The present study showed that the level of histamine increased by PMACI was significantly lowered by treatment with BV. As calcium is a crucial secondary messenger in mast cell signaling, the regulation of intracellular calcium is critical to histamine release by mast cells. Intracellular calcium level correlates with mast cell degranulation, exocytosis from mast cells and the expression of inflammatory cytokines (42). Therefore, reduced intracellular calcium may be involved in the inhibitory effect of BV on histamine release. In addition, $\mathrm{BV}$ significantly inhibited the production and mRNA expression of TNF- $\alpha$, IL- 6 and IL-1 $\beta$ in the PMACI-stimulated HMC- 1 cells and in the compound 48/80-induced anaphylaxis model in mice. These data suggested that the effect of BV on pro-inflammatory cytokines may assist in preventing and treating mast cell-mediated inflammatory diseases. Among the results of the mRNA expression of pro-inflammatory cytokines in the anaphylactic shock animal model, the high concentration of BV effectively reduced the level of IL-6 expressed, even in a normal state. As IL-6 is a multifunctional cytokine involved in a broad spectrum of biological events, and increased levels of IL-6 are observed in several human inflammatory diseases, it may be that BV has a potent suppressive effect on inflammatory responses. However, further clarification of the molecular mechanisms underlying the function if IL-6 and the inhibition of IL-6 signaling is required.

MAPKs are present in numerous cells and tissues, and consist of three major protein kinase families: ERK, p38 and JNK. The MAPK signaling cascade regulates important 
cellular processes, which transduce extracellular stimuli into intracellular responses, including gene expression, cell proliferation, cell survival and death, and cell mobility (5). It has been reported that MAPK signal transduction pathways control inflammatory responses and cytokine production (43). The prototypical MAPK phosphorylation cascade consists of an MAPK kinase kinase (MAPKKK or MEKK), an MKK and an MAPK. MAPKKK phosphorylates and activates MKK, which in turn phosphorylates MAPK. MKKs in the MAPK cascade act as dual-specificity kinases and activate MAPKs through double phosphorylation of the threonine-X-tyrosine motif in the activation loop. During this phosphorylation relay, the input signal can be amplified through the MAPK cascade and the activated MAPKs eventually modify the phosphorylation of a specific set of downstream target proteins, including transcription factors and other signaling components, leading to the activation of downstream genes (44). In the present study, the data showed that cells pre-treated with BV suppressed the PMACI-induced phosphorylation of MAPKs and MKKs, compared with the cells treated with PMACI alone, however, the total levels of MAPK and MKK were unaffected. In the case of MKK7, an upstream factor of JNK, PMACI did not induce its phosphorylation and BV pre-treatment had no effect (data not shown). These data revealed that the effect of BV on mast cell-mediated inflammatory reactions may be mediated through MAPK pathways, result in cytokine production.

Allergic inflammation is associated with an increased expression of multiple inflammatory proteins, which are regulated by STAT transcription factors that are activated by Janus kinases and a large number of cytokines present in the pro-allergic environment (45). STAT3 is important in the signaling involved in mast cells and mediates mast cell degranulation (46). STAT3 acquires DNA-binding activity through dimerization and then translocates to the nucleus, where it binds to gene promoters and activates transcription. Tyrosine phosphorylation is required for STAT3 dimerization, nuclear translocation and DNA binding. In addition, phosphorylation of a conserved carboxy-terminal serine residue (Ser727) has been shown to enhance STAT3 transcriptional activation $(47,48)$. The Ser727 phosphorylation of STAT3 either inhibits tyrosine phosphorylation or increases tyrosine dephosphorylation (49). These reports indicate that each residue of STAT3 has a different role and activates different targets. In the present study, BV had no effect on the activation of $\mathrm{NF}-\kappa \mathrm{B}$, which is crucial in the regulation of allergic inflammatory responses (50). As BV inhibited the PMACI-stimulated phosphorylation of MAPKs, which contribute to the transmission of extracellular signals that can result in the phosphorylation of various transcription factors and alterations in gene expression (51), the present study focused on examining the effects of BV on STAT3 as it is a critical component in multiple aspects of allergic disease. The resulting data indicated that STAT3 was activated on Ser727 in PMACI-induced HMC-1 cells, whereas it was activated on Tyr705 in the compound 48/80-induced anaphylactic shock animal model. Based on these data, it was hypothesized that the inhibitory effects of BV on STAT3 signaling depend on tissue specificity in the mast cell-mediated allergic inflammatory response.
BV is the venom stored by bees within their venom sacs for self-defense, and has traditionally been used in oriental medicine to relieve pain and treat inflammatory diseases (52). $\mathrm{BV}$ is composed of various peptides, enzymes and non-peptide components. The peptides are mainly composed of apamin, melittin, MCD peptide and adolapinm, and the enzymes include phospholipase A2, hyaluronidase, acid phosphomonoesterase, $\alpha$-d-glucosidase and lypophospholipase. The non-peptide components consist of histamine, dopamine and noradrenaline. Although it has been reported that melittin, a major component of $\mathrm{BV}$, induces paw edema in mice, and that the administration of $\mathrm{BV}$ into the hind paw produces local inflammation, BV components have been the subject of several investigations using diverse methodologies in an effort to determine their anti-inflammatory effects $(53,54)$. BV and its components have been used to treat various conditions, including arthritis, rheumatism, back pain and skin diseases, by regulating inflammatory responses (55). In the present study, although the BV complex was used, future investigations aim to investigate the use of major active components of BV to overcome the limitations of complexity and to identify which components act to cause these effects. In addition, further investigations are required to identify the effect of each component of BV on the regulation of STATs during an allergic inflammatory response, with the present study contributing to this further understanding.

In the present study, it was shown that BV suppressed the phosphorylation of MAPKs, MKKs and STAT3 in PMACI-stimulated HMC-1 cells and in an anaphylactic shock animal model. Furthermore, in addition to the inhibition of histamine release in PMACI-stimulated HMC-1 cells, BV inhibited the production and mRNA expression of pro-inflammatory cytokines in the cells and animal model. Therefore, the results of the present study suggested that BV has an anti-allergic inflammatory effect and that this effect of BV may be an effective modulator of mast cell-mediated allergic inflammatory responses.

\section{Acknowledgements}

The authors would like to thank Professor Jae-Young Um (Kyung Hee University, Republic of Korea) for providing the HMC-1 cells.

\section{Funding}

This study was supported by the Basic Science Program through the National Research Foundation of Korea funded by the Ministry of Education (grant no. NRF-2017R1C1B2008617).

\section{Availability of data and materials}

All data generated or analyzed during this study are included in this published article.

\section{Authors' contributions}

YMK, KSC, ML, and HJA conceived and designed the experiments. YMK and IHK performed the experiments and analyzed the data with KSC and HJA. HB 
contributed samples. ML and YBK contributed reagents, materials and analytical tools. YMK and KSC wrote the manuscript. All authors read and approved the final manuscript.

\section{Ethics approval and consent to participate}

All procedures were performed in accordance with university guidelines and approved by the Ethical Committee for Animal Care and the Use of Laboratory Animals, Korean Medicine, Sangji University (approval no. 2015-11).

\section{Consent for publication}

Not applicable.

\section{Competing interests}

The authors declare that they have no competing interests.

\section{References}

1. Hong MH, Kim JH, Bae H, Lee NY, Shin YC, Kim SH and Ko SG: Atractylodes japonica Koidzumi inhibits the production of proinflammatory cytokines through inhibition of the $\mathrm{NF}-\kappa \mathrm{B} / \mathrm{I} \kappa \mathrm{B}$ signal pathway in HMC-1 human mast cells. Arch Pharm Res 33: 843-851, 2010.

2. Sohn Y, Han NY, Lee MJ, Cho HJ and Jung HS: [6]-Shogaol inhibits the production of proinflammatory cytokines via regulation of NF- $\mathrm{KB}$ and phosphorylation of JNK in HMC-1 cells. Immunopharmacol Immunotoxicol 35: 462-470, 2013.

3. Kim JY and Ro JY: Signal pathway of cytokines produced by reactive oxygen species generated from phorbol myristate acetate-stimulated HMC-1 cells. Scand J Immunol 62: 25-35, 2005.

4. Jeong HJ, Hong SH, Park RK, An NH and Kim HM: Ethanol induces the production of cytokines via the $\mathrm{Ca}^{2+}$, MAP kinase, HIF-1 $\alpha$, and NF- $\kappa$ B pathway. Life Sci 77: 2179-2192, 2005.

5. Ko YJ, Kim HH, Kim EJ, Katakura Y, Lee WS, Kim GS and Ryu CH: Piceatannol inhibits mast cell-mediated allergic inflammation. Int J Mol Med 31: 951-958, 2013.

6. Jeon YD, Kee JY, Kim DS, Han YH, Kim SH, Kim SJ, Um JY and Hong SH: Effects of Ixeris dentata water extract and caffeic acid on allergic inflammation in vivo and in vitro. BMC Complement Altern Med 15: 196, 2015.

7. Ichijo H: From receptors to stress-activated MAP kinases. Oncogene 18: 6087-6093, 1999.

8. Favata MF, Horiuchi KY, Manos EJ, Daulerio AJ, Stradley DA, Feeser WS, Van Dyk DE, Pitts WJ, Earl RA, Hobbs F, et al: Identification of a novel inhibitor of mitogen-activated protein kinase kinase. J Biol Chem 273: 18623-18632, 1998.

9. Zou J, Wang R, Li R, Kong Y, Wang J, Ning X, Zhang L, Wang S, Hu X and Bao Z: The genome-wide identification of mitogen-activated protein kinase kinase (MKK) genes in Yesso scallop Patinopecten yessoensis and their expression responses to bacteria challenges. Fish Shellfish Immunol 45: 901-911, 2015.

10. Glosson NL, Bruns HA and Kaplan MH: Wheezing and itching: The requirement for STAT proteins in allergic inflammation. JAKSTAT 1: 3-12, 2012.

11. Samavati L, Rastogi R, Du W, Hüttemann M, Fite A and Franchi L: STAT3 tyrosine phosphorylation is critical for interleukin 1 beta and interleukin- 6 production in response to lipopolysaccharide and live bacteria. Mol Immunol 46: 1867-1877, 2009.

12. Michaud-Levesque J, Bousquet-Gagnon N and Béliveau R: Quercetin abrogates IL-6/STAT3 signaling and inhibits glioblastoma cell line growth and migration. Exp Cell Res 318: 925-935, 2012.

13. Zolfagharian H, Mohajeri M and Babaie M: Honey bee venom (Apis mellifera) contains anticoagulation factors and increases the blood-clotting time. J Pharmacopuncture 18: 7-11, 2015.

14. Ali MAA-SM: Studies on bee venom and its medical uses. Int J Adv Res Technol 1: 69-83, 2012.

15. Hwang DS, Kim SK and Bae H: Therapeutic effects of Bee Venom on immunological and neurological diseases. Toxins 7: 2413-2421, 2015
16. Kim WH, An HJ, Kim JY, Gwon MG, Gu H, Park JB, Sung WJ Kwon YC, Park KD, Han SM and Park KK: Bee venom inhibits porphyromonas gingivalis lipopolysaccharides-induced pro-inflammatory cytokines through suppression of NF- $\kappa \mathrm{B}$ and AP-1 signaling pathways. Molecules 21: E1508, 2016.

17. Zolfagharian $\mathrm{H}$, Mohajeri $\mathrm{M}$ and Babaie $\mathrm{M}$ : Bee venom (Apis Mellifera) an effective potential alternative to gentamicin for specific bacteria strains: Bee venom an effective potential for bacteria. J Pharmacopuncture 19: 225-230, 2016.

18. Nipate SS, Hurali PB and Ghaisas MM: Evaluation of anti-inflammatory, anti-nociceptive, and anti-arthritic activities of Indian Apis dorsata bee venom in experimental animals: Biochemical, histological, and radiological assessment. Immunopharmacol Immunotoxicol 37: 171-184, 2015.

19. Kim KH, Kum YS, Park YY, Park JH, Kim SJ, Lee WR, Lee KG, Han SM and Park KK: The protective effect of bee venom against ethanol-induced hepatic injury via regulation of the mitochondria-related apoptotic pathway. Basic Clin Pharmacol Toxicol 107: 619-624, 2010.

20. Russell PJ, Hewish D, Carter T, Sterling-Levis K, Ow K, Hattarki M, Doughty L, Guthrie R, Shapira D, Molloy PL, et al: Cytotoxic properties of immunoconjugates containing melittin-like peptide 101 against prostate cancer: In vitro and in vivo studies. Cancer Immunol Immunother 53: 411-421, 2004.

21. Son DJ, Lee JW, Lee YH, Song HS, Lee CK and Hong JT: Therapeutic application of anti-arthritis, pain-releasing, and anti-cancer effects of bee venom and its constituent compounds. Pharmacol Ther 115: 246-270, 2007.

22. Park HJ, Lee SH, Son DJ, Oh KW, Kim KH, Song HS, Kim GJ, Oh GT, Yoon DY and Hong JT: Antiarthritic effect of bee venom: Inhibition of inflammation mediator generation by suppression of NF-kappaB through interaction with the p50 subunit. Arthritis Rheum 50: 3504-3515, 2004.

23. Shin SH, Kim YH, Kim JK and Park KK: Anti-allergic effect of bee venom in an allergic rhinitis mouse model. Biol Pharm Bull 37: 1295-1300, 2014.

24. Huh JE, Baek YH, Lee MH, Choi DY, Park DS and Lee JD: Bee venom inhibits tumor angiogenesis and metastasis by inhibiting tyrosine phosphorylation of VEGFR-2 in LLC-tumor-bearing mice. Cancer Lett 292: 98-110, 2010.

25. Choi MS, Park S, Choi T, Lee G, Haam KK, Hong MC, Min BI and $\mathrm{Bae} \mathrm{H}$ : Bee venom ameliorates ovalbumin induced allergic asthma via modulating $\mathrm{CD} 4{ }^{+} \mathrm{CD} 25^{+}$regulatory $\mathrm{T}$ cells in mice. Cytokine 61: 256-265, 2013.

26. An HJ, Lee WR, Kim KH, Kim JY, Lee SJ, Han SM, Lee KG, Lee CK and Park KK: Inhibitory effects of bee venom on Propionibacterium acnes-induced inflammatory skin disease in an animal model. Int J Mol Med 34: 1341-1348, 2014.

27. Livak KJ and Schmittgen TD: Analysis of relative gene expression data using real-time quantitative PCR and the 2(-Delta Delta C(T)) method. Methods 25: 402-408, 2001.

28. Choi YH, Chai OH, Han EH, Choi SY, Kim HT and Song CH: Lipoic acid suppresses compound 48/80-induced anaphylaxis-like reaction. Anat Cell Biol 43: 317-324, 2010.

29. Chai OH, Shon DH, Han EH, Kim HT and Song CH: Effects of Anemarrhena asphodeloides on IgE-mediated passive cutaneous anaphylaxis, compound 48/80-induced systemic anaphylaxis and mast cell activation. Exp Toxicol Pathol 65: 419-426, 2013.

30. Cho MS, Park WS, Jung WK, Qian ZJ, Lee DS, Choi JS, Lee DY, Park SG, Seo SK, Kim HJ, et al: Caffeic acid phenethyl ester promotes anti-inflammatory effects by inhibiting MAPK and NF- $\kappa \mathrm{B}$ signaling in activated HMC-1 human mast cells. Pharm Biol 52: 926-932, 2014.

31. Li L, Jin G, Jiang J, Zheng M, Jin Y, Lin Z, Li G, Choi Y and Yan G: Cornuside inhibits mast cell-mediated allergic response by down-regulating MAPK and NF- $\mathrm{KB}$ signaling pathways. Biochem Biophys Res Commun 473: 408-414, 2016.

32. Dérijard B, Raingeaud J, Barrett T, Wu IH, Han J, Ulevitch RJ and Davis RJ: Independent human MAP-kinase signal transduction pathways defined by MEK and MKK isoforms. Science 267: 682-685, 1995.

33. Chae HS, Kim YM and Chin YW: Atractylodin inhibits interleukin- 6 by blocking NPM-ALK activation and MAPKs in HMC-1. Molecules 21: E1169, 2016.

34. Granato M, Rizzello C, Gilardini Montani MS, Cuomo L, Vitillo M, Santarelli R, Gonnella R, D'Orazi G, Faggioni A and Cirone M: Quercetin induces apoptosis and autophagy in primary effusion lymphoma cells by inhibiting PI3K/AKT/mTOR and STAT3 signaling pathways. J Nutr Biochem 41: 124-136, 2017. 
35. Choi YH, Yan GH, Chai OH, Lim JM, Sung SY, Zhang X, Kim JH, Choi SH, Lee MS, Han EH, et al: Inhibition of anaphylaxis-like reaction and mast cell activation by water extract from the fruiting body of Phellinus linteus. Biol Pharm Bull 29: 1360-1365, 2006.

36. Li GZ, Chai OH, Lee MS, Han EH, Kim HT and Song CH: Inhibitory effects of Houttuynia cordata water extracts on anaphylactic reaction and mast cell activation. Biol Pharm Bull 28: 1864-1868, 2005.

37. Minai-Fleminger $\mathrm{Y}$ and Levi-Schaffer F: Mast cells and eosinophils: The two key effector cells in allergic inflammation. Inflamm Res 58: 631-638, 2009.

38. Zampeli E and Tiligada E: The role of histamine $\mathrm{H} 4$ receptor in immune and inflammatory disorders. Br J Pharmacol 157: 24-33, 2009.

39. Kim MH, Seo JH, Kim HM and Jeong HJ: Zinc oxide nanoparticles, a novel candidate for the treatment of allergic inflammatory diseases. Eur J Pharmacol 738: 31-39, 2014.

40. Foster JR: The functions of cytokines and their uses in toxicology. Int J Exp Pathol 82: 171-192, 2001.

41. Saukkonen K, Sande S, Cioffe C, Wolpe S, Sherry B, Cerami A and Tuomanen E: The role of cytokines in the generation of inflammation and tissue damage in experimental gram-positive meningitis. J Exp Med 171: 439-448, 1990.

42. Ye J, Piao H, Jiang J, Jin G, Zheng M, Yang J, Jin X, Sun T, Choi YH, Li L and Yan G: Polydatin inhibits mast cell-mediated allergic inflammation by targeting PI3K/Akt, MAPK, NF- $\mathrm{BB}$ and Nrf2/HO-1 pathways. Sci Rep 7: 11895, 2017.

43. Nam SY, Kim HY, Yoou MS, Kim AH, Park BJ, Jeong HJ and Kim HM: Anti-inflammatory effects of isoacteoside from Abeliophyllum distichum. Immunopharmacol Immunotoxicol 37 : 258-264, 2015

44. Song Q, Li D, Dai Y, Liu S, Huang L, Hong Y, Zhang H and Song F: Characterization, expression patterns and functional analysis of the MAPK and MAPKK genes in watermelon (Citrullus lanatus). BMC Plant Biol 15: 298, 2015.

45. Barnes PJ: Transcription factors in airway diseases. Lab Invest 86: 867-872, 2006
46. Siegel AM, Stone KD, Cruse G, Lawrence MG, Olivera A, Jung MY, Barber JS, Freeman AF, Holland SM, O'Brien M, et al: Diminished allergic disease in patients with STAT3 mutations reveals a role for STAT3 signaling in mast cell degranulation. J Allergy Clin Immunol 132: 1388-1396, 2013

47. Ivashkiv LB: Jak-STAT signaling pathways in cells of the immune system. Rev Immunogenet 2: 220-230, 2000.

48. Schuringa JJ, Jonk LJ, Dokter WH, Vellenga E and Kruijer W: Interleukin-6-induced STAT3 transactivation and Ser727 phosphorylation involves Vav, Rac-1 and the kinase SEK-1/MKK-4 as signal transduction components. Biochem J 347: 89-96, 2000.

49. Decker T and Kovarik P: Serine phosphorylation of STATs. Oncogene 19: 2628-2637, 2000.

50. Krishnamurthy P and Kaplan MH: STAT6 and PARP family members in the development of T cell-dependent allergic inflammation. Immune Netw 16: 201-210, 2016.

51. Vanden Berghe W, Plaisance S, Boone E, De Bosscher K, Schmitz ML, Fiers W and Haegeman G: p38 and extracellular signal-regulated kinase mitogen-activated protein kinase pathways are required for nuclear factor-kappaB p65 transactivation mediated by tumor necrosis factor. J Biol Chem 273: 3285-3290, 1998.

52. Jang HS, Kim SK, Han JB, Ahn HJ, Bae H and Min BI: Effects of bee venom on the pro-inflammatory responses in RAW264.7 macrophage cell line. J Ethnopharmacol 99: 157-160, 2005.

53. Hartman DA, Tomchek LA, Lugay JR, Lewin AC, Chau TT and Carlson RP: Comparison of antiinflammatory and antiallergic drugs in the melittin- and D49 PLA2-induced mouse paw edema models. Agents Actions 34: 84-88, 1991.

54. Lariviere WR and Melzack R: The bee venom test: A new tonic-pain test. Pain 66: 271-277, 1996.

55. Chung KS, An HJ, Cheon SY, Kwon KR and Lee KH: Bee venom suppresses testosterone-induced benign prostatic hyperplasia by regulating the inflammatory response and apoptosis. Exp Biol Med 240: 1656-1663, 2015. 